\title{
To What Extent Does Musical Aptitude Influence Foreign Language Pronunciation Skills? A Multi-Factorial Analysis of Japanese Learners of English
}

\author{
Matthew Dolman ${ }^{1, *} \&$ Ryan Spring ${ }^{1}$ \\ ${ }^{1}$ School of International Cultural Studies, Tohoku University, Sendai, Japan \\ *Corresponding author: School of International Cultural Studies, Tohoku University, Sendai, Japan. E-mail: \\ matthewdolman@gmail.com
}

Received: August 31, 2014

Accepted: September 17, 2014

Online Published: October 20, 2014

doi:10.5430/wjel.v4n4p1

URL: http://dx.doi.org/10.5430/wjel.v4n4p1

\begin{abstract}
This study looks at the influence of musical aptitude on learners' pronunciation abilities in a foreign language. While there have been many studies that have claimed a link between the two (Slevc \& Miyake 2006, Milovanov 2010, etc.), some studies suggest that this link may not be as strong as initially thought (Jackendoff, 2009, etc.). This study examines the pronunciation abilities of Japanese University students of similar English level and varying musical aptitude, but conducts more in depth statistical analysis than previous studies by comparing specific musical abilities, such as pitch, loudness, rhythm, tone and timing, with specific problematic pronunciation points, the English sounds $/ \mathrm{r} /, / 1 /, / \mathrm{v} /,[\theta]$ and $[\varnothing]$. The results of our experimentation indicated a statistically significant correlation between musical timing aptitude and the ability to pronounce $r$ and 1 sounds, but no other significant correlations, indicating that perhaps only specific musical abilities have influence on specific aspects of pronunciation.
\end{abstract}

Keywords: foreign language learning; musical aptitude; pronunciation

\section{Introduction}

The link between language and music has been a contentious issue and one that has received a resurgence of research attention in recent years. A great deal has been said about the similarities between the two (e.g. Jackendoff, 2009, Deutsch et al. 2011, Brandt, 2012), but the extent to which language and music are connected in the mind remains far from fully understood. Recently, the connection between language and music has been argued to be found not only in how the two might act similarly in the human brain (Lutz 2012, etc.), but also in foreign language learning, particularly in the learning of foreign language pronunciation (Slevc \& Miyake 2006, Milovanov 2010, etc.).

The main aim of this research is to add to the growing body of studies providing support for the correlation between musical aptitude and foreign language skills. It concentrates on specific domains within language and music, namely, pronunciation and pitch, duration (time), rhythm, loudness and tonal memory efficacy. These are examined using the "Seashore Musical Aptitude Test" (Seashore, Lewis, \& Saetveit, 1960a, b, 2003) and a specially developed pronunciation test based on previous studies (particularly Slevc \& Miyake 2006, and Milovanov 2010). The study observes the participant's "musical aptitude", which needs to be distinguished from music lessons and musicianship. Musical aptitude can be defined as an untaught, natural ability. This distinction is required in order for research to make an impact in this field, a fact that has been highlighted by researchers in the past (e.g. Schellenberg and Peretz, 2008). Up to date, clear distinctions have not always been made in such studies, making it difficult for assumptions to be made.

\section{Previous studies}

2.1 The Connection between Music and Language

The topic of music and language has generated plenty of discussion over the years, from as early as Rousseau's 
(1781) proposition that language evolved from song to Darwin's (1871) claim that, "musical sounds afforded one of the bases for the development of language" (p. 639). Despite these early opinions, in more recent times, music and language started to become seen as two separate entities that evolved independently and had different societal functions. For example, Brandt et al. (2012) set about giving music a comprehensive definition: an essential starting point in standardizing results and resolving conflicting data in comparative research between language and music.

Brandt et al. (2012) began by drawing upon various universal assumptions that have been made regarding the world's indigenous musical traditions, such as the discrimination of consonance and dissonance. Dissonance is generally considered as unpleasant, particularly in Western music, however in some other cultures it is appreciated for its "beauty". Musical similarities between cultures have been found to be relatively uncommon, even when it comes to emotional attribution. It has been found in some cultures that the distinction between language and music is somewhat vague; whistling (Carreiras et al., 2005) and drumming (Gleick, 2011) are used as communicative devices amongst tribes in parts of Africa, while even poetry could be said to contain similar rhythmic attributes to music (e.g., Jackendoff, 2009). The sheer variety and lack of limitation in music lead them to propose that "music is creative play with sound" and that "depending on how one listens, the same stimuli can be perceived as language or music" (Brandt et al. 2012, p. 3).

Furthermore, investigations have been carried out showing that, when repeated several times, the spoken word can resemble song rather than speech. Deutsch et al. (2011) performed two experiments, the first of which involved playing ten different presentations of a phrase and asking participants to make judgments on how it sounded from "exactly like speech" to "exactly like singing". When all of the presentations of the phrase were matching, the results clearly leaned towards song rather than speech. On the other hand, if the presentations differed in pitch or the order of syllables changed, the participants did not make such an observation. The second experiment required participants to listen to presentations of a phrase from one to ten times and repeat what they ultimately heard. Subsequent to hearing one presentation, participants repeated the phrase back as speech, however, after ten presentations they repeated it back as song. The results demonstrated a shift of attention from the meaning to the melodic features of the phrases' prosodic inflection.

Despite the similarities, some researchers have urged caution in drawing strong comparisons between language and music. Jackendoff (2009) argues that, though language and music share a number of general characteristics, it "does not indicate a particularly close relation that makes them distinct from other cognitive domains" (p. 203). He does, however, point to other researchers, such as Patel (2008), who have analyzed similar data and come to conclusions more indicative of a correlation. Before dismissing the connections between language and music, Jackendoff (2009) believes that accounts of other capacities need to be analyzed in order to generate an impartial foundation for comparison. One such capacity that has begun to be explored is the link between language learning and music, as discussed in the next section.

\subsection{Music and Foreign Language Learning}

There have been a number of studies suggesting that music contributes to first language learning cross-culturally (Friederici 2006, Cheng et al. 2012, Wermke \& Mende 2009, etc.). Aside from these studies, there are numerous claims suggesting that musical training and expertise offer a variety of linguistically relevant advantages (Slevc 2012, Milovanov 2010, etc.). For example, musical education has been said to lead to advantages in the processing of prosody: musicians show greater sensitivity than non-musicians to emotional prosodic cues (Lima and Castro, 2011) and better recognition of subtle prosodic variations at the end of utterances in both their native and in a foreign language (Schön et al. 2004, Marques et al. 2007). Musical training is also associated with better perception of subtle timing contrasts in both native and foreign speech (Marie et al. 2011, Sadakata \& Sekiyama 2011).

Marie et al. (2011) examined the impact of musical proficiency on the metric and semantic aspects of speech processing. Musicians were required to listen to short sentences ending in tri-syllabic words that were semantically and/or metrically congruous or incongruous. The data was analyzed and compared with previously collected data from non-musicians. With regard to the processing of meter, results revealed that musical expertise influenced "the automatic detection of the syllable temporal structure, the integration of metric structure and its influence on word comprehension" (p. 294). On the other hand, the results showed that musical proficiency did not have an impact on the semantic level of processing.

The advantages mentioned above also have practical benefits, including the ability to perceive and learn second language phonology (Milovanov 2010, Slevc and Miyake 2006, Delogu et al. 2010, etc.). For example, Milovanov 2010 tested three different groups of Finnish students (English philology students, Choir members, and nonmusical university students) using the Seashore musical aptitude test and a pronunciation test. However, though Milovanov 
(2010) found the participants with better musical aptitude were more successful in the English pronunciation test, research has confirmed more and more strongly that the mother tongue of a speaker has a strong influence on the way a second language is learned and used (e.g. Kellerman, 1984; Kellerman and Sharwood Smith, 1986; Ringbom, 1987; Odlin, 1989; Perdue, 1993), and thus, these results could potentially be specific to the linguistic differences in the languages used in his study - Finnish and English.

In order to get a broader view of how music ability can affect second language pronunciation ability, we now point to some papers that have looked at the effects of music on Japanese students studying English as a foreign language. Recently, Kondo (2012) compared verbal and non-verbal phonological memory with L2 pronunciation skills using a group of 36 Japanese university students. A positive relationship was found between the two, which Kondo claims "reinforces the findings of the few studies that imply a relationship between L2 pronunciation and musical ability" ( $p$. 539). Although there was a musical aspect to the phonological memory testing, the lack of a standardized test, in addition to the use of a sole, non-native judge when analyzing the pronunciation test, make the results somewhat unreliable.

Additionally, Tanaka and Nakamura (2004) carried out a study on 30 Japanese university students studying English as a foreign language concentrating on the relationship between auditory memory and second language speaking skill. They found evidence to support the hypothesis that the memory for both verbal and musical tasks affects proficiency of second language pronunciation, however their music test did not allow them to answer the question of which musical skills affect which domain of language acquisition. This is a question that the present study may be able to shed more light on.

Slevc and Miyake (2006) attempted to shed some light on individual differences in adult second language acquisition by using more thorough testing methods than previous studies in the field. They conclude, after determining participants' musical ability by administering subtests taken from the Wing Measures of Musical Talents (Wing, 1968) and their language proficiency through a number of assessments, that "musical ability may well be related to proficiency in L2 phonology" ( $p$ 7). However, their work looked at native Japanese speakers living abroad, rather than those who represent the majority in Japan, who are only exposed to English in the classroom.

Thus, though the previous studies presented in this section provide a very good overview for the connection between language and music, and more specifically how skills of the two can be correlated, more standardized research is still needed to show a more specific link between the two. This paper thus aims to measure the extent to which musical aptitude may correlate with the learning of a foreign language, specifically in terms of pronunciation. It will stem from the standardized practices of Milovanov (2010) and the findings of Slevc and Miyake (2006), but attempt to look further into what aspects of music might have the largest effects on pronunciation, based on studies such as Westphal, Leutenegger and Wagner (1969) and Dexter and Omwake (1934) which suggest that some aspects play a larger role in second language learning than others. Based on the results of these studies, I present the following hypothesis:

(1) Native Japanese speakers studying English as a foreign language with superior musical aptitude perform better on an English pronunciation test.

(2) There are different correlations between high performance in specific sections of the musical aptitude test (pitch, duration (time), timbre, rhythm, loudness and tonal memory efficacy) and pronunciation.

\section{Experimentation}

\subsection{Methodology}

We gathered 34 Japanese university students (22 female, 12 male) to participate in the experiment reported in this paper, which consisted of taking a musical aptitude test, a pronunciation test, and completing a background questionnaire. All students were right-handed and studying literature, education or medicine at Tohoku University (no English majors). All of the participants were aged between 18 and 20 years old and were born and raised in Japan. The participants had studied English as a foreign language since junior high school and had not received additional private language training before or during that time. Non-Japanese students, students who had lived in a foreign country for a significant amount of time (more than one month) or received language training outside of school, were not included in the analysis in this study. Similarly, no students with hearing impairments, or who could not properly complete the tests were considered in analysis.

All students were taking the same English class, putting them at roughly the same English skill level, although the 
levels of each student varied slightly. A number of the students had taken private music lessons for several years in the past. However, due to the fact that we wanted to test the correlation between musical aptitude, which can to some degree be innate, and foreign language pronunciation learning, and because we measured musical aptitude in this experiment, the presence or absence of musical training was not given separate, special analysis in the current study.

Though the definition of the term "aptitude" has been the source of debate in previous papers (Gordon, 1979; Schellenberg and Peretz, 2008), in the interest of consistency, we judged musical aptitude with a test used in similar recent studies (e.g. Milovanov, 2009). The test used is called the "Seashore Musical Aptitude Test" and is a standardized test based on the notion that musical aptitude is shared between a number of distinct talents: pitch, duration (time), timbre, rhythm, loudness and tonal memory efficacy. Despite this test being the oldest standardized music test available (first published in 1919, and revised in 1939) (Nardo et al., 2009), it has been a prevalent method of measuring musical talent up to the present day (e.g. Westphal, Leutenegger and Wagner, 1969; Tucker, 2000; Milovanov, 2009).

The Seashore Musical Aptitude Test consists of five initial subtests, in which the participant must compare two notes or rhythmic patterns and mark on their answer sheet whether or not they vary. This change may be related to how high or low the note is, or how long or short the note is, and so on. In the final subtest, tonal memory efficacy, the participant is required to listen to a sequence of pairs of successive tones, and to ascertain within each pair, which tone in the second sequence alters in pitch from its equivalent tone in the first one. Seashore (1919) deemed musical talent to be a gift of nature and as such, he created a test accessible for subjects regardless of age or musical experience utilizing the aforementioned subtests, which measure immediate sensory acts that do not develop with training. While there have been criticisms of this test (specifically, Wing, 1970) and a number of other musical aptitude tests have been created over the years (e.g. Wing's Standardized Tests of Musical Intelligence (1968), Gordon's Primary Measures of Music Audiation (1979), etc.), consistency in the testing of musical ability is fundamental in finding meaningful results, and as this experiment is modeled after Milovanov's (2010) study, we also chose to utilize the Seashore Musical Aptitude Test.

The pronunciation test in this study consists of thirty words each containing at least one of six problematic phonemes for Japanese speakers of English at the beginning, middle or end of the word: the voiced $[\theta]$ and unvoiced [ $\delta]$ "th" sound, $/ \mathrm{r} /, / 1 /, / \mathrm{f} /$, and $/ \mathrm{v} /$. None of the chosen phonemes appear in the Japanese syllabary, which make them exceptionally difficult to distinguish or articulate for native speakers of the language (e.g. Goto, 1971; Miyawaki et al., 1975; Mochizuki, 1981). The presence and absence of certain phonemes across languages is a common obstacle in language learning, but is not impossible to master with sufficient training and practice (e.g. Flege 1987).

English education in Japan is taught with a concentration on American English and accordingly, a native speaker of American English was selected to record the words. A five-second pause was inserted between each word to allow participants time to think and then imitate the word. The pronunciation test was prepared with the intention of being presented orally with no written assistance for the participant. A similar test was used by Milovanov (2008) as one of three pronunciation tasks; in the phonemic listening and discrimination tasks, participants performed equally well regardless of musical ability. The pronunciation test, on the other hand, demonstrated a clear correlation between musical ability and pronunciation skill and was thus employed in this study. The words used in this study were recorded alphabetically and are listed in table 1 , below (phonemes being tested in bold characters).

Table 1. Pronunciation Test Word List

\begin{tabular}{llllll}
\hline Ark & Bath & Bathe & Beef & Car & Even \\
Face & Finance & Fought & Have & Lamp & Lice \\
Lick & Milk & Mother & Move & Often & Radar \\
Rice & Right & Smooth & These & Thick & Think \\
Though & Thumb & Van & Vest & Yellow & Youth \\
\hline
\end{tabular}

The pronunciation test was administered individually to each participant through headphones in a language laboratory. Participants were instructed to first listen to the English word and then attempt to pronounce it into the provided voice recorder. Participants were encouraged to attempt every word, even if they were not completely sure of what they had heard. If a participant did not answer, those results were removed from our data analysis.

Subsequent to the testing, the recordings were presented to three native speakers of English (two American, one British) and each word was judged on a scale of zero to five (zero being unintelligible, five being equal to a native speaker). Individual scores for each selection were then found by averaging the three scores from the three judges for 
each test item.

\subsection{Results}

The data from the musical aptitude test was collected and quantified for analysis. The timbre section of the test was removed from the study due to an error during the testing that rendered the results unusable. From the remaining five sections, the participants generally recorded high scores, with a group average of 180.64 (out of a possible 210) with a standard deviation of 15.13. The individual pronunciation test ratings of the three native judges were also quantified and averaged for each participant. The average score for the group was 85.83 (out of a possible 150) with a standard deviation of 14.45. The pronunciation of the words 'lamp,' 'these' and 'thumb' proved particularly difficult for a large proportion of the students. These results are summarized in Table 2, with a breakdown of the average scores in each musical subtest listed as well. The individual scores for each participant are displayed in Figure 1.

Table 2. Average Participant Scores for All Tests

\begin{tabular}{lcc}
\hline \multicolumn{1}{c}{ Test type } & Score (Avg.) / Max. Score & Standard Deviation \\
\hline Pitch & $44.55 / 50$ & 3.58 \\
Rhythm & $26.44 / 30$ & 2.78 \\
Loudness & $42.35 / 50$ & 3.84 \\
Time & $43.02 / 50$ & 4.10 \\
Tonal Memory & $26.38 / 30$ & 3.84 \\
Musical Aptitude (overall) & $180.64 / 210$ & 15.13 \\
Pronunciation Test (overall) & $85.83 / 150$ & 14.45 \\
\hline
\end{tabular}

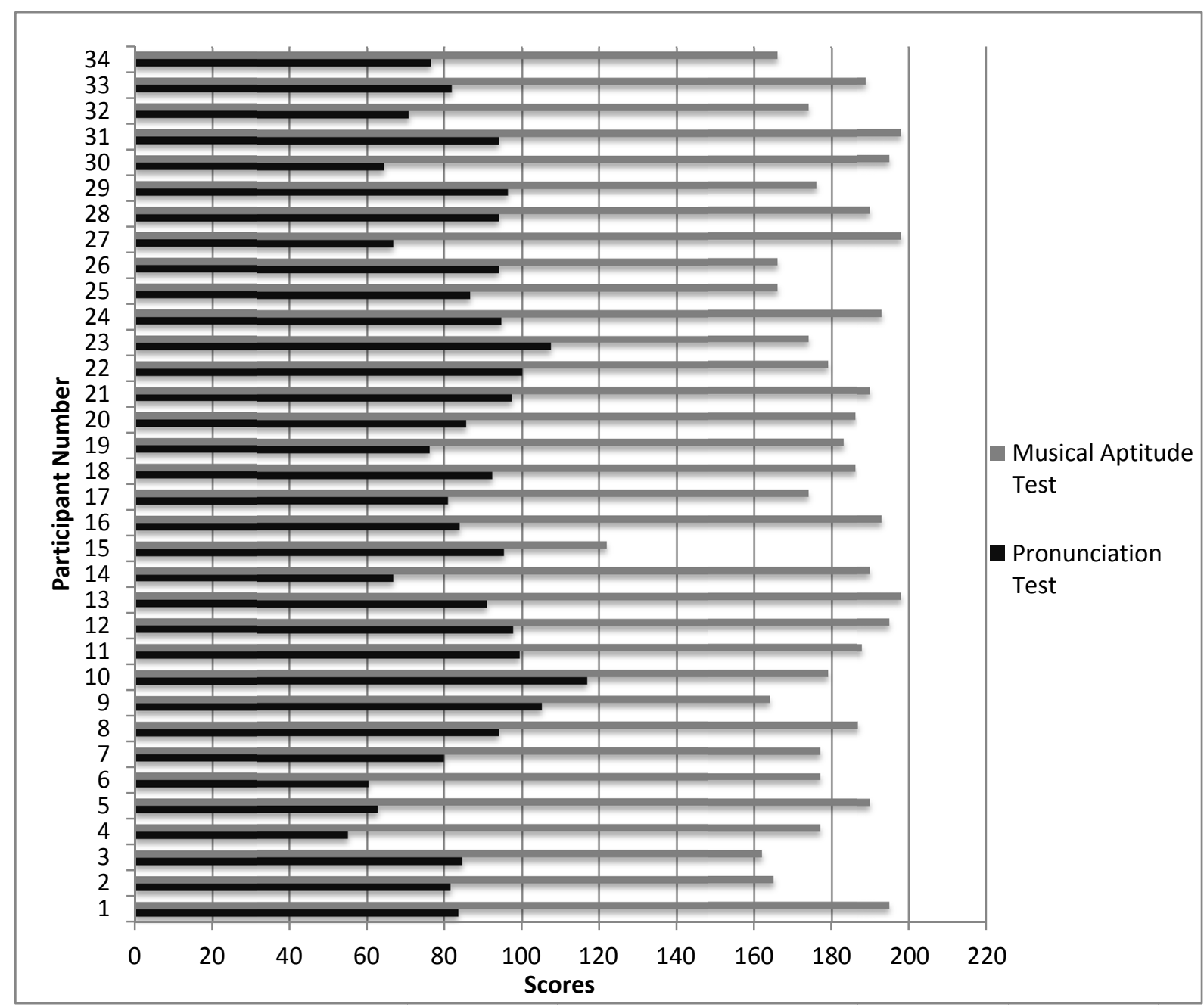

Figure 1. Individual Scores in Musical Aptitude and Pronunciation Test 
The participants were then divided into two separate groups based on their scores: one for high musical aptitude and the other for low musical aptitude. The averages from both groups were then used to carry out a one-way ANOVA, which showed a significant result between the two groups $(F[1,34]=43.91, p=0.001)$. The same two groups were then used for analyzing the pronunciation scores. This allowed for a comparative analysis between the two sets of results in order to test the first hypothesis as in Milovanov (2010). However, there were no significant differences between the two groups with regard to overall pronunciation ability $(F[1,34]=0.193, p=0.664)$. The results differ to those of previous studies, for example, Milovanov (2010), who found a significant correlation between general musical aptitude and pronunciation skills $(\mathrm{r}=-0.641, \mathrm{p}<0.001)$.

Further analyses were required to test the second hypothesis that pronunciation skill correlates with specific musical talents. First of all, as with the initial analysis, high and low groups were created for each subtest of the musical aptitude test and checked for significance using a one-way ANOVA test. These all showed significant results as seen in table 3 below.

Table 3. Average Group Scores for Musical Aptitude Test

\begin{tabular}{llll}
\hline Test type & High group (avg.) & Low group (avg.) & Significance \\
\hline Overall & 191.33 & 168.62 & $\mathrm{~F}[1,34]=43.91, \mathrm{p}<0.001$ \\
Pitch & 47 & 41.46 & $\mathrm{~F}[1,34]=46.07, \mathrm{p}<0.001$ \\
Loudness & 45 & 39.7 & $\mathrm{~F}[1,34]=29.13, \mathrm{p}<0.001$ \\
Rhythm & 28.66 & 24.68 & $\mathrm{~F}[1,34]=32.46, \mathrm{p}<0.001$ \\
Time & 46.16 & 39.5 & $\mathrm{~F}[1,34]=61.45, \mathrm{p}<0.001$ \\
Tonal Memory & 29.05 & 23.7 & $\mathrm{~F}[1,34]=30.19, \mathrm{p}<0.001$ \\
\hline
\end{tabular}

These groups were then compared to each group's overall pronunciation scores to see if any particular musical ability helped overall pronunciation more than any other group. However, we found no significant results for any of the categories compared against the overall pronunciation: pitch $(F[1,34]=0.987, p 0.328)$, loudness $(F[1,34]=0, p$ $0.991)$, rhythm $(F[1,34]=0.782, p 0.383)$, time $(F[1,34]=0.213, \quad p 0.648)$ and tonal memory $(F[1,34]=0.076, p$ $0.784)$.

Consequently, the participants were then analyzed with regard to their performance in pronouncing certain problematic phonemes. Table 4 shows which words were used from the pronunciation test for each analysis. The individual word scores suggest that these phonemes were the most challenging for the participants.

Table 4. Words Used in Phoneme Analysis

\begin{tabular}{ll}
\hline Target phoneme(s) & Words \\
\hline$/ \mathrm{r} /$ and $/ \mathrm{l} /$ & Ark, lamp, lice, lick, milk, radar, rice, right, yellow \\
{$[\theta]$ and $[\varnothing]$} & Bath, bathe, mother, smooth, these, thick, think, though, thumb, youth \\
$/ \mathrm{v} /$ & Even, have, move, van, vest \\
\hline
\end{tabular}

The scores from these words were scrutinized in the same groups as the overall pronunciation scores to enable a comparison between the participants overall musical aptitude scores, and then with each separate section of the musical aptitude test.

The first problematic phoneme under scrutiny was $/ \mathrm{v} /$, however each analysis revealed no significant results. [ $\theta$ ] and $[ð]$ similarly offered no evidence to support the initial hypothesis. Table 5 offers a summary of the results of each separate analysis.

Table 5. T-test Results for $/ \mathrm{v} /$ and $[\theta]$ and [ð] Phonemes

\begin{tabular}{|c|c|c|c|}
\hline Test type & $/ \mathrm{v} /$ & {$[\theta]$ and $[ð$} & \\
\hline Overall & $\mathrm{F}[1,34]=0.51, \quad \mathrm{p} 0.48$ & $\mathrm{~F}[1,34]=0.096$ & p 0.758 \\
\hline Pitch & $\mathrm{F}[1,34]=0.388, \quad \mathrm{p} 0.538$ & $\mathrm{~F}[1,34]=0.389$ & $\mathrm{p} 0.537$ \\
\hline Loudness & $F[1,34]=0.776, \quad$ p 0.385 & $\mathrm{~F}[1,34]=0.056$ & $\mathrm{p} 0.814$ \\
\hline Rhythm & $\mathrm{F}[1,34]=2.301, \quad \mathrm{p} 0.139$ & $\mathrm{~F}[1,34]=0.123$, & p 0.728 \\
\hline Time & $\mathrm{F}[1,34]=0.001, \quad \mathrm{p} 0.97$ & $\mathrm{~F}[1,34]=0.031$, & p 0.862 \\
\hline Tonal Memory & $\mathrm{F}[1,34]=0.92, \quad \mathrm{p} 0.345$ & $\mathrm{~F}[1,34]=0.165$ & p 0.687 \\
\hline
\end{tabular}


Contrastingly, the final analysis of the /r/ and /1/ phonemes, notoriously difficult for Japanese learners of English (e.g. Goto, 1971; Miyawaki et al., 1975; Mochizuki, 1981), offered the one and only significant result found in this study. A correlation was found between $/ \mathrm{r} /$ and $/ 1 /$ pronunciation ability and the time subtest of the Seashore Musical Aptitude test $(\mathrm{F}[1,34]=5.298, \mathrm{p} 0.028)$, while all others did not show any statistical significance: pitch $(\mathrm{F}[1,34]=$ $0.618, \mathrm{p} 0.438)$, loudness $(\mathrm{F}[1,34]=1.462, \mathrm{p} 0.236)$, rhythm $(\mathrm{F}[1,34]=0.188, \mathrm{p} 0.668)$ and tonal memory $(\mathrm{F}$ $[1,34]=0.304, \quad p$ 0.585). In other words, the participants who performed better with words containing $/ \mathrm{r} /$ and $/ 1 /$ phonemes also achieved superior scores in the time subtest of the musical aptitude test.

\section{Discussion}

The hypotheses developed in this study were based on previous research in the field, but were only partially supported by the experimental findings. These results perhaps demonstrate the need for caution when discussing the extent of the relationship between language and music (as urged by Jackendoff 2009), but also posit numerous avenues for discussion and future research such as more cross-cultural research, which could help to make more concrete generalizations (a call echoed by Brandt 2012).

Although the first hypothesis was based on studies carried out by Slevc and Miyake (2006) and Milovanov (2010), it was not supported by the analysis of the pronunciation test and musical aptitude test results in this study. Slevc and Miyake (2006) found zero order correlations suggesting that musical ability may indeed be related to proficiency in L2 phonology, while Milovanov found a correlation between general musical aptitude (as shown by the Seashore test) and pronunciation skills $(\mathrm{r}=-0.641, \mathrm{p}<0.001)$. Consequently, the question of why these results differ must be examined.

First and foremost, the variances in the studies need to be scrutinized. One of the most notable of these is the groups of participants under investigation. While Slevc and Miyake (2006) utilized an alternative musical aptitude test (Wing Measures of Musical Talents) and studied native Japanese speakers who had lived in the United States for at least six months, the Milovanov (2010) study is easier to equate the current study to. The testing methods for both musical aptitude and pronunciation were imitated to an extent in this study so that comparisons could be made. The significant differences lie in the fact that Milovanov selected forty-six native speakers of Finnish, who made up three separate groups: English philology students, choir members, and non-musical university students. Alternatively, the current study focuses on one group of Japanese native speakers with a variety of musical experience and a virtually identical history of English language education.

This raises two interesting issues: firstly, is the effect of musical ability on facilitating pronunciation skill only visible when there are significant differences in musical aptitude between the participants (e.g. music majors vs. non-music majors)? A large proportion of students achieved relatively high scores on the musical aptitude test in this study (a group average of 180.64 out of a possible 210). If these scores were more varied, a significant result may have been found in the comparative analysis with the pronunciation test. Interestingly, in Milovanov's (2010) study, non-musical students performed poorest in the time subtest, while the musical students (choir members) achieved their second highest scores of the test in the same section, although the author did not highlight this fact. This is significant because the students who performed better in the musical aptitude test were ultimately found to have greater pronunciation skills in this test.

Secondly, one must wonder if the respective native languages of the participants in this study and that of Milovanov (2010) influence the results. As mentioned in section 2.6, one of the goals of this study is to shed some light on potential differences on how music affects learners of English from different language backgrounds. Judging by the results of the separate studies, it could be suggested that Finnish students benefitted more from superior musical aptitude skill than the Japanese students. However, the difference in the results of this study and Milovanov (2010) could also be related to the various phonological similarities and differences in Finnish, Japanese and English.

Despite their typological differences, both Finnish and Japanese have a number of words with the same or similar pronunciation. Moreover, they are both agglutinative languages, but vary morphologically (Isei-Jaakkola, 2004). Problematic phonemes for both Finnish and Japanese learners of English differ, for example the $/ \mathrm{r} /$ and $/ 1 /$ sounds that many Japanese English learners struggle with already exist in the Finnish language. The Finnish syllable structure is also said to be more complex than that of Japanese, containing a larger number of combinations of vowels and consonants within syllable and word frames (Isei-Jaakkola, 2004). Taking this into consideration, it could be suggested that Finnish language learners may be more flexible in terms of learning foreign language pronunciation, particularly English - as it has a similar syllable structure, than Japanese learners. This flexibility may 
ultimately alter the effectiveness of musical ability's influence on pronunciation skill. In other words, the differences between ones mother tongue and the foreign language being studied may change the amount musical ability contributes toward pronunciation skill.

Extensive research has been carried out on native language interference on the target language (e.g. Dechert, 1983; Ellis, 1997), though his has not been related to musical ability. Studies such as Dulay et al. (1982) and Dordick (1996) (among others) have proposed that the probability of performance related interference increases when specific points in L2 are especially detached from L1, such as those that exist between English and Japanese. Performance related tasks such as the pronunciation test carried out in this paper may then prove more difficult for Japanese students who are learning English than speakers of European languages who are learning English, thus diminishing the positive effect of musical aptitude.

The effect of language differences may also be relevant with regard to the results of the second hypothesis - that particular aspects of musical aptitude have more correlation with pronunciation ability than others. As with the first, the second hypothesis was based on previous studies showing positive correlations, this time between high performance in specific sections of the Seashore Musical Aptitude Test and a pronunciation test.

Though Dexter and Omwake (1934) found a correlation between a pitch subtest and the French accent rating of native English speakers, French historically had a heavy influence on English following its introduction in England in the $11^{\text {th }}$ century (e.g. Barry, 2002), and as a result the two languages share many grammatical features and include many cognates. The positive correlation in the current study is more specific than those previously cited. No correlations were found between the pronunciation test as a whole and the individual musical aptitude subtests. However, the much deliberated /r/ and /1/ phonemes (e.g. Goto, 1971; Miyawaki et al., 1975; Mochizuki, 1981) correlated with the time (duration) subtest of Seashore Musical Aptitude Test $(\mathrm{F}[1,34]=5.298, \quad \mathrm{p} 0.028)$.

It is interesting to note the differences in timing between the languages here. English has a stress rhythm, and segmentation by English listeners is centered on stress, while the rhythm of Japanese is based on the mora, a sub-syllabic unit (Otake et al., 1993). The fact that English is a stress-centered language means that syllables can be either strong or weak, and weak syllables contain reduced vowels (commonly schwa) (Otake et al., 1993). Japanese learners' English stress patterns demonstrate interference from Japanese pitch accent patterns, particularly in compounds and phrases, which often results in a delayed stress. The interference caused by the Japanese mora-timed rhythm makes it a difficult task for Japanese learners to master the stress timing of English. The additional difficulty of producing weak forms of vowels, and inserting vowels between consonants also augment this struggle (Taniguchi, 2009). According to the results of this study, it could be suggested that high scores in the time subtest enabled participants to overcome the durational variations between English and Japanese with words containing /r/ and /1/ phonemes. A larger study examining groups of Japanese students with more disparate levels of musical ability would be interesting to determine whether high scores in this subtest can help with words including phonemes other than $/ \mathrm{r} /$ and $/ 1 /$.

As pointed out in the results section, in Milovanov's (2010) study, non-musical students performed poorest in the time subtest, while the musical students (choir members) achieved their second highest scores of the test in the same section. This is significant because the students who performed better in the musical aptitude test were ultimately found to have greater pronunciation skills in this test. Despite Milovanov's study finding a more general correlation between pronunciation and musical aptitude, the conclusions drawn in the current paper appear to show significance in the musical aptitude test results that are not discussed in her paper.

Both Japanese and Finnish students who performed better in the time section of the musical aptitude test had either superior overall pronunciation ability, or higher scores with words targeting specific problematic phonemes. This is particularly fascinating when the rhythmic and durational features of the respective languages are considered. Firstly, Japanese and Finnish have quantity distinction between both short and long vowels and consonants (Isei-Jaakkola, 2010). The length of vowels and consonants are essential in distinguishing certain words, which is not the case in languages like English. Moreover, Finnish, like Japanese, is often cited as a mora-timed language, rather than a stress-timed language such as English (Aoyama, 2001).These points suggest that musical timing may help to bridge the gap between languages with contrasting rhythmic and durational features, although, depending on the language, may have a more crucial impact in combination with other musical abilities on overall pronunciation.

The importance of duration and timing in language learning should be emphasized; in both music and speech, temporal patterning of events generate hierarchically organized rhythms that are perceived as metrical (Palmer and Hutchins, 2006). There have also been suggestions that there are similar neural mechanisms for processing meter in music and speech (Patel, 2008; Marie et al., 2011). Sabater (1991) claims that stress and rhythm are supra-segmental 
aspects that give the overall shape to a word or sequence and are "the backbone of English pronunciation" (p. 147). In order for a word to be comfortably intelligible, the correct accentual pattern or rhythm must be achieved. Moreover, Sabater (1991) asserts that by misplacing the main stress of a word, or a lack of appropriate weakening of unstressed syllables, the shape of a word can become distorted, thus becoming incomprehensible. Stress can also influence phonological variation, which offers a premise for how musical duration may benefit pronunciation of specific phonemes. Sabater (1991) offers the three English words "exit," "exhibition," and "exist" as examples of how the pronunciation of the letter " $x$ " is determined exclusively by the point of stress. If stress is placed on the preceding syllable, the cluster will be voiceless however, if it is placed on the subsequent syllable, the cluster will be voiced. This example offers a credible argument in suggesting that understanding the correct position or timing of stress in a word enables a speaker to clearly pronounce English words. Therefore, if neural mechanisms for processing meter in speech and music are shared (Patel, 2008; Marie et al., 2011), musical ability in the durational domain could be said to assist this.

\section{Conclusion}

As mentioned in the previous section, the hypotheses of this study were only partially supported by the experimental data presented in this study. Though overall musical aptitude did not correlate to overall pronunciation ability for Japanese learners of English, a correlation was found between the ability of the learners to pronounce $/ \mathrm{r} /$ and $/ 1 /$, and the time subtest of the Seashore Musical Aptitude test. These results suggest that there are some potential benefits to having musical ability when learning foreign language pronunciation, but does also point to the fact that some caution should be used before assuming that all types of musical ability will help every aspect of learning pronunciation.

Importantly, the results of this study suggest that further research is still needed in the relationship between language and music, particularly on that of pronunciation skills compared with different musical domains. Future research should continue to become more cross-cultural (as also suggested by Brandt 2012), using similar testing methods to the current paper and participants from various language backgrounds. Such future studies would enable comparative analyses in order to understand the effects of different aspects of music on various parts of foreign language learning.

\section{References}

Barry, A. (2002). Linguistic Perspectives on Language and Education. Greenwood Publishing Group.

Brandt, A., Gebrian, M., \& Slevc, R. (2012). Music and early language acquisition. Front Psychology, 2012, 3-327. http://dx.doi.org/10.3389/fpsyg.2012.00327

Carreiras, M., Lopez, J., Rivero, F., \& Corina, D. (2005). Linguistic perception: neural processing of a whistled language. Nature, 433, 31-32. http://dx.doi.org/10.1038/433031a

Cheng, Y., Lee, S. Y., Chen, H. Y., Wang, P. Y., \& Decety, J. (2012). Voice and emotion processing in the human neonatal brain. Journal of Cognitive Neuroscience, Jun, 1411-9. http://dx.doi.org/10.1162/jocn_a_00214

Darwin, C. (1871). The Descent of Man, and Selection in Relation to Sex. London: John Murray.

Dechert, H.W. (1983). How a story is done in a second language. Strategies in Interlanguage Communication. Longman, London.

Delogu, F., Lampis, G., \& Belardinelli, M. O. (2010). From melody to lexical tone: musical ability enhances specific aspects of foreign language perception. European Journal of Cognitive Psychology, 22, 46-61. http://dx.doi.org/10.1080/09541440802708136

Deutsch, D., Henthorn, T., \& Lapidis, R. J. (2011). Illusory transformation from speech to song. Acoustics Society of America, Apr, 2245-52. http://dx.doi.org/10.1121/1.3562174

Dexter, E. S., \& Omwake, K. T. (1934). The relation between pitch discrimination and accent in modern languages. Journal of Applied Psychology, 18, 267-271. http://dx.doi.org/10.1037/h0070125

Dexter, E. S. (1934). Pitch Discrimination and French Accent on the High School level. Journal of Applied Psychology, 18, 717-720. http://dx.doi.org/10.1037/h0072734

Dordick, M. (1996). Testing for a hierarchy of the communicative interference value of ESL errors. System, 24, 
299-308. http://dx.doi.org/10.1016/0346-251X(96)00023-1

Dulay, H., Burt, M., \& Krashen, S. (1982). Language Two. Oxford University Press, New York.

Ellis, R. (1997). Second Language Acquisition. Oxford University Press, Oxford.

Flege, J. E. (1987). A critical period for learning to pronounce foreign languages? Applied Linguistics, 8, 162-177. http://dx.doi.org/10.1093/applin/8.2.162

Friederici, A. D. (2006). The neural basis of language development and its impairment. Neuron, Dec, 941-52. http://dx.doi.org/10.1016/j.neuron.2006.12.002

Gleick, J. (2011). The Information: A History, a Theory, a Flood. New York, NY: Pantheon.

Goto, H. (1971). Auditory perception by normal Japanese adults of the sounds "L" and "R". Neuropsychologia, 9, 317-323. http://dx.doi.org/10.1016/0028-3932(71)90027-3

Isei-Jaakkola, T. (2004). Lexical quantity in Japanese and Finnish. Publications (48) of Department of Phonetics, University of Helsinki.

Isei-Jaakkola, T. (2010). Durational variability of vowel quantity for Japanese, Finnish and Czech. Proceedings of Speech Prosody 2010, Chicago.

Jackendoff, R. (2009). Parallels and Non-Parallels between Language and Music. Music Perception, 26, 195-204. http://dx.doi.org/10.1525/MP.2009.26.3.195

Kellerman, E. (1984). The Empirical Evidence for the Influence of the L1 in Interlanguage. In Davies, A., Criper, C. and Howatt, A. (Eds.). Interlanguage. Edinburgh: Edinburgh University Press.

Kellerman, E., \& Sharwood Smith, M. (1986). Crosslinguistic Influence in Second Language Acquisition. Oxford: Pergamon Press.

Kondo, A. (2012). Phonological Memory and L2 Pronunciation Skills. In A. Stewart \& N. Sonda, Eds., JALT2011 Conference Proceedings. Tokyo: JALT.

Lima, C. F., \& Castro, S. L. (2011). Speaking to the trained ear: musical expertise enhances the recognition of emotions in speech prosody. Emotion, Oct, 1021-31. http://dx.doi.org/10.1037/a0024521

Lott, D. (1983). Analysing and counteracting interference errors. ELT Journal, 37(3), 256-261. http://dx.doi.org/10.1093/elt/37.3.256

Lutz, J. (2012). The relationship between music and language. Frontiers in Psychology, April. http://dx.doi.org/10.3389/ fpsyg.2011.00230

Marie, C., Magne, C., \& Besson, M. (2011). Musicians and the metric structure of words. Journal of Cognitive Neuroscience, Feb, 294-305. http://dx.doi.org/10.1162/jocn.2010.21413

Marques, C., Moreno, S., Castro, S. L., \& Besson, M. (2007). Musicians detect pitch violation in a foreign language better than nonmusicians: behavioral and electrophysiological evidence. Journal of Cognitive Neuroscience, Sep, 1453-63. http://dx.doi.org/10.1162/jocn.2007.19.9.1453

Miyawaki, K. et al. (1975). An affect of linguistic experience: The discrimination of [r] and [1] by native speakers of Japanese and English. Perception \& Psychophysics, 18, 331-340. http://dx.doi.org/10.3758/BF03211209

Mochizuki, M. (1981). The identification of /r/ and /1/ in natural and synthesized speech. Journal of Phonetics, 9, 283-303.

Odlin, T. (1989). Language Transfer. Cambridge: Cambridge University Press.

Otake, T., Hatano, G., Cutler, A., \& Mehler, J. (1993). Mora or Syllable? Speech segmentation in Japanese. Journal of Memory and Language, 32, 258-278. http://dx.doi.org/10.1006/jmla.1993.1014

Oxford, R. (1993). Research Update on L2 Listening. System, 21, 205-11. http://dx.doi.org/10.1016/0346-251X(93)90042-F

Palmer C., \& Hutchins S. (2006). What is musical prosody? Psychology of Learning and Motivation. Amsterdam: Elsevier Press

Patel, A. D. (2008). Music, language, and the brain. Oxford University Press

Perdue, C. (1993). Adult Language Acquisition: Cross-linguistic Perspectives. Cambridge: Cambridge University Press. 
Ringbom, H. (1987). The Role of the First Language in Foreign Language Learning. Clevedon, Philadelphia: Multilingual Matters Ltd.

Rousseau, J. J. (1781/1993). Essai Sur L'origine des Langues. Paris: Flammarion.

Sabater, M. S. (1991). Stress and Rhythm in English. Revista Alicantina de Estudios Ingleses, 4, 145-62.

Sadakata, M., \& Sekiyama, K. (2011). Enhanced perception of various linguistic features by musicians: a cross-linguistic study. Acta Psychologica (Amst), Sep, 1-10. http://dx.doi.org/10.1016/j.actpsy.2011.03.007

Schellenberg, E. G. (2006). Exposure to music: the truth about the consequences. In The Child as Musician: A Handbook of Musical Development. McPherson, G.E., (Eds.). Oxford University Press.

Schellenberg, E. G., \& Peretz, I. (2008). Music, language and cognition: Unresolved issues. Trends in Cognitive Science, 12, 45-46. http://dx.doi.org/10.1016/j.tics.2007.11.005

Schön, D., Magne, C., \& Besson, M. (2004). The music of speech: music training facilitates pitch processing in both music and language. Psychophysiology, May, 341-9. http://dx.doi.org/10.1111/1469-8986.00172.x

Seashore, C. E. (1956). The Seashore measures of musical talents. New York: Columbia Phonograph.

Slevc, L. R. (2012). Language and music: sound, structure, and meaning. Cognitive Science, 3, 483-492. http://dx.doi.org/10.1002/wcs.1186

Slevc, L. R., \& Miyake, A. (2006). Individual differences in second-language proficiency: does musical ability matter? Psychological Science, Aug, 675-81. http://dx.doi.org/10.1111/j.1467-9280.2006.01765.x

Tanaka A., \& Nakamura K. (2004). Auditory memory and proficiency of second language speaking: a latent variable analysis approach. Psychology Report, 95, 723-34. http://dx.doi.org/10.2466/PR0.95.7.723-734

Taniguchi, M. (2009). English Phonetics: Japanese learners' weak points in English pronunciation, rhythm and intonation. [Lecture Notes] Retrieved from http://www.seinangu.ac.jp/syakai/school/pdf/090822taniguti.pdf

Wermke, K., \& Mende, W. (2009). Musical elements in human infants' cries: in the beginning is the melody. Musical Science, 13, 151-175. http://dx.doi.org/10.1016/j. cub.2009.09.064

Westphal, E. M., Ralph, R., Leutenegger \& Dorothea L. Wagner. (1969). Some psycho-acoustic and intellectual correlates of achievement in German language learning of junior high school students. Modern Language Journal, 53, 258-266. http://dx.doi.org/10.1111/j.1540-4781.1969.tb07032.x

Wing, H. D. (1968). Tests of musical ability and appreciation: An investigation into the measurement, distribution, and development of musical capacity. Cambridge University Press, London. 